\title{
Parasitizing of rose tortrix moth population [Archips rosana (L.)] in apple orchards with integrated plant protection in Wielkopolska
}

\author{
Spasożytowanie populacji zwójki różóweczki [Archips rosana (L.)] \\ w sadach jabłoniowych z integrowaną ochroną roślin w Wielkopolsce
}

\author{
Hanna Piekarska-Boniecka, Paweł Trzciński
}

\begin{abstract}
Summary
The study was in apple orchards with integrated plant protection in the vicinity of Poznan in 2009-2010. The aim was to determine the level of parasitizing of the rose tortrix moth [Archips rosana (L.)] in its pupae stage by different parasitoid families. The rose tortrix moth is definitely a dominant species among phytophages in the "leaf” tortrix group in the apple orchards of western Wielkopolska. The abundance of the moth was reduced by three families of parasitoids, namely Ichneumonidae and Chalcididae (Hymenoptera) and Tachinidae (Diptera). The pupae were parasitized in 4.7\% in 2009 by Ichneumonidae and Tachinidae, while in 2010 the parasitization percentage was $23.6 \%$ respectively for the three parasitoid families. A high effectiveness of Ichneumonidae in controlling the abundance of tortrix moth was found, and the parasitization level was $4.7 \%$ and $15.7 \%$. A high effectiveness of Itoplectis maculator (F.) (Pimplinae) in controlling the abundance of the tortrix was shown as compared with the other species of Ichneumonidae. In 2009 this species was the only one to reduce the moth abundance and parasitized the pest in $4 \%$, and in 2010 it reduced the abundance of the moth to the greatest extent, i.e. by $11.7 \%$.
\end{abstract}

Key words: apple orchard, parasitizing, Archips rosana, Ichneumonidae, Chalcididae, Tachinidae

\section{Streszczenie}

Badania prowadzono w latach 2009-2010, w sadach jabłoniowych okolic Poznania, w których stosowano integrowaną metodę ochrony roślin. Celem badań było określenie stopnia spasożytowania zwójki róźóweczki [Archips rosana (L.)] w stadium poczwarki przez poszczególne rodziny parazytoidów. Zwójka różóweczka należy do zdecydowanego dominanta wśród fitofagów zaliczanych do zwójek „liściowych" występujących w sadach jabłoniach, w zachodniej Wielkopolsce.

Liczebność zwójki została ograniczona przez trzy rodziny parazytoidów, do których należały Ichneumonidae i Chalcididae (Hymenoptera) oraz Tachinidae (Diptera). Poczwarki zwójki zostały spasożytowane w 4,7\% w 2009 roku przez Ichneumonidae i Tachinidae, natomiast w 2010 roku w 23,6\% przez trzy rodziny parazytoidów. Stwierdzono wysoką efektywność Ichneumonidae w regulacji liczebności zwójki, ponieważ obserwowano pasożytowanie w 4,7\% i w 15,7\%. Wykazano wysoką skuteczność gatunku Itoplectis maculator (F.) (Pimplinae) w obniżeniu liczebności zwójki w odniesieniu do pozostałych gatunków Ichneumonidae. W 2009 roku był on jedynym gatunkiem, który obniżył jej liczebność i spasożytował ją w 4\%, a w 2010 roku ograniczył jej liczebność w najwyższym stopniu, bo w $11,7 \%$.

Słowa kluczowe: sad jabłoniowy, pasożytowanie, Archips rosana, Ichneumonidae, Chalcididae, Tachinidae

\footnotetext{
Uniwersytet Przyrodniczy w Poznaniu

Katedra Entomologii i Ochrony Środowiska

Dąbrowskiego 159, 60-594 Poznań

boniecka@up.poznan.pl
} 


\section{Wstęp / Introduction}

Zwójka różóweczka [Archips rosana (L.)] należy do grupy gatunków fitofagicznych, tzw. zwójek „liściowych” (Lepidoptera, Tortricidae), która występuje bardzo licznie w sadach jabłoniowych i w innych uprawach sadowniczych (Piekarska-Boniecka i wsp. 2006, 2008; Płuciennik i Olszak 2010; Janiuk i wsp. 2011). Jest również gatunkiem uszkadzającym drzewa i krzewy ozdobne rosnące w zieleni miejskiej. Żeruje bardzo często na gatunkach roślin z rodzin: Aceraceae, Betulaceae, Cornaceae, Leguminosae, Oleceae, Salicaeae, Rosaceae i Ulmaceae (Polat i Tozlu 2010). Zwójka ta występuje na tyle licznie w środowisku sadowniczym, że wymaga chemicznego zwalczania. Podjęto więc badania mające ustalić w jakim stopniu liczebność tego gatunku może być ograniczana przez entomofagi w sadach jabłoniowych, w których prowadzi się integrowaną ochronę roślin.

Celem badań było określenie stopnia spasożytowania zwójki różóweczki w stadium poczwarki przez poszczególne rodziny parazytoidów oraz ustalenie efektywności gatunków z rodziny Ichneumonidae (Hymenoptera, Apocrita) w obniżeniu jej liczebności.

\section{Materiały i metody / Materials and methods}

Badania prowadzono w latach 2009-2010 w sadach jabłoniowych w Wielkopolsce. W 2009 roku był to sad w okolicach Kórnika, a w 2010 roku w Pamiątkowie. Powierzchnia sadów wynosiła odpowiednio 11,5 ha oraz 9 ha. W sadzie w okolicach Kórnika badania prowadzono w kwaterze wielkości 0,5 ha, na 10-letnich jabłoniach odmian Golden Delicious, Melrose i Szampion, a w sadzie w Pamiątkowie w kwaterze o powierzchni 0,6 ha, na 7-letnich nasadzeniach jabłoni odmian Jonagold i Topaz. W sadach stosowano integrowaną ochronę jabłoni przed szkodnikami i chorobami. W sadzie w Kórniku przeprowadzono 2 zabiegi ochrony roślin przed szkodnikami, stosując Nurelle D 550 EC, a w sadzie w Pamiątkowie tylko jeden zabieg, stosując Mospilan 20 SP. W okresie od maja do lipca każdego roku badań przeglądano żerowiska gąsienic zwójki i wybierano poczwarki, a następnie hodowano je indywidualnie pod izolatorami w sadzie.

\section{Wyniki i dyskusja / Results and discussion}

Łącznie w latach 2009-2010, w sadach jabłoniowych zebrano 1559 poczwarek zwójki różóweczki. Stwierdzono trzy rodziny parazytoidów: Ichneumonidae (Hymenoptera), Chalcididae (Hymenoptera) oraz Tachinidae (Dipera). Przedstawiciele rodzin Ichneumonidae i Tachinidae obniżyły liczebność zwójki w obu latach badań, natomiast parazytoidy z rodziny Chalcididae tylko w roku 2010. Ogólne spasożytowanie poczwarek zwójki wyniosło $13,6 \%$.

W 2009 roku, w sadzie jabłoniowym w okolicach Kórnika zebrano 827 poczwarek zwójki. Parazytoidy z rodzin Ichneumonidae i Tachinidae obniżyły jej liczebność w bardzo niskim stopniu, ponieważ spasożytowały ją tylko w 4,7\%. Ichneumonidae wykazały wyższą efektywność w ograniczeniu liczebność zwójki w stosunku do Tachinidae, ponieważ pasożytowały ją w 4,3\%. Tachinidae obniżyły jej liczebność jedynie w $0,4 \%$ (rys. 1).

W sadzie jabłoniowym w okolicach Kórnika twierdzono tylko jeden gatunek parazytoida $\mathrm{z}$ rodziny Ichneumonidae. Był to Itoplectis maculator (F.) (Pimplinae), który spasożytował populację zwójki w $4 \%$ (rys. 1).

W 2010 roku, w sadzie jabłoniowym w Pamiątkowie zebrano 732 poczwarki zwójki. Parazytoidy z rodzin Ichneumonidae, Tachinidae oraz Chalcididae spasożytowały zwójkę w wysokim stopniu, bo w 23,6\%. Ichneumonidae okazały się najbardziej efektywnymi parazytoidami w stosunku do pozostałych rodzin parazytoidów i obniżyły jej liczebność w 15,7\%. Udział Tachinidae w spasożytowaniu zwójki wyniósł 6\%, a Chalcididae tylko 1,9\% (rys. 2).

W sadzie jabłoniowym, w Pamiątkowie stwierdzono 6 gatunków parazytoidów $\mathrm{z}$ rodziny Ichneumonidae. Zdecydowanie dominował gatunek I. maculator (Pimplinae), który obniżył liczebność zwójki w najwyższym stopniu, bo w $11,7 \%$. Pozostałe gatunki parazytoidów wystąiły nielicznie i spasożytowały zwójkę w niewielkim stopniu, bo od 0,1 do $1 \%$ (rys. 2), a były to: Gelis albipalpus Thoms. (Cryptinae), Phaeogenes semivulpinus (Grav.) (Ichneumoninae), Chorineus longicornis Thoms. (Metopiinae), Apechthis quadridentata (Thoms.) i A. rufata (Gmel.) (Pimplinae) (rys. 2). Gatunki z rodzaju Apechthis i I. maculator należą do endoparazytoiów poczwarkowych Lepidoptera, Coleoptera, Diptera i Hymenoptera. Gatunek G. albipalpus jest endoparazytoidem poczwarek Lepidoptera oraz hypeparazytoidem pasożytującym Ichneumonoidea. Gatunki $P$. semivulpinus i Ch. longicornis należą do endoparazytodów larwalno-poczwarkowych przeważnie Lepidoptera.

Badania wykazały bardzo niskie spasożytowanie zwójki różóweczki w 2009 roku czego nie potwierdzają wcześniejsze badania Piekarskiej-Bonieckiej i wsp. (2006, 2008) dotyczące ograniczenia liczebności tego gatunku w sadach jabłoniowych na terenie Wielkopolski. Tak niskie spasożytowanie tego fitofaga można thumaczyć przede wszystkim warunkami pogodowymi, które panowały w maju i czerwcu 2009 roku, gdyż miesiące te należały do ciepłych i bardzo suchych. Niskie pasożytowanie zwójki mogło również wynikać $\mathrm{z}$ dwukrotnie przeprowadzonych w 2009 roku zabiegów ochrony roślin. W 2010 roku wykazano zdecydowanie wyższe spasożytowanie zwójki, które koresponduje z wynikami wcześniejszych badań Piekarskiej-Bonieckiej i wsp. (2006, 2008). Ograniczenie liczebności zwójki w granicach od 20,3 do 33,2\% jest najczęściej spotykaną regulacją naturalną tej populacji w sadach jabłoniowych na terenie Wielkopolski (Piekarska-Boniecka i wsp. 2006, 2008).

Wszystkie stwierdzone rodziny parazytoidów były już wcześniej wykazywane jako entomofagi tej zwójki (Piekarska-Boniecka i wsp. 2006, 2008).

W wyniku przeprowadzonych badań stwierdzono wysoką efektywność parazytoidów z rodziny Ichneumonidae $\mathrm{w}$ obniżaniu liczebności zwójki. W obu latach badań Ichneumonidae spasożytowały ją w najwyższym stopniu. Wysoką efektywność tych parazytoidów w regulacji liczebności tego gatunku wykazały również wcześniejsze badania Piekarskiej-Bonieckiej i wsp. (2006, 2008). 


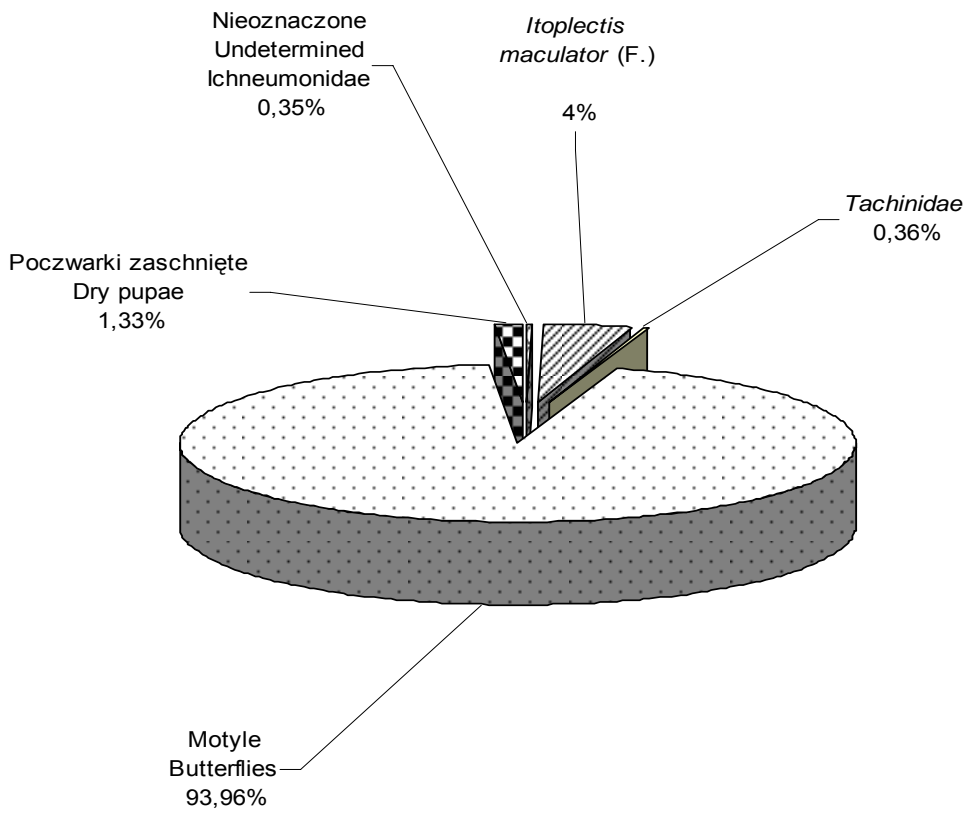

Rys. 1. Udział rodzin i gatunków Ichneumonidae w spasożytowaniu poczwarek A. rosana w 2009 roku Fig. 1. The share of families and Ichneumonidae species in parasitizing of $A$. rosana pupae in 2009

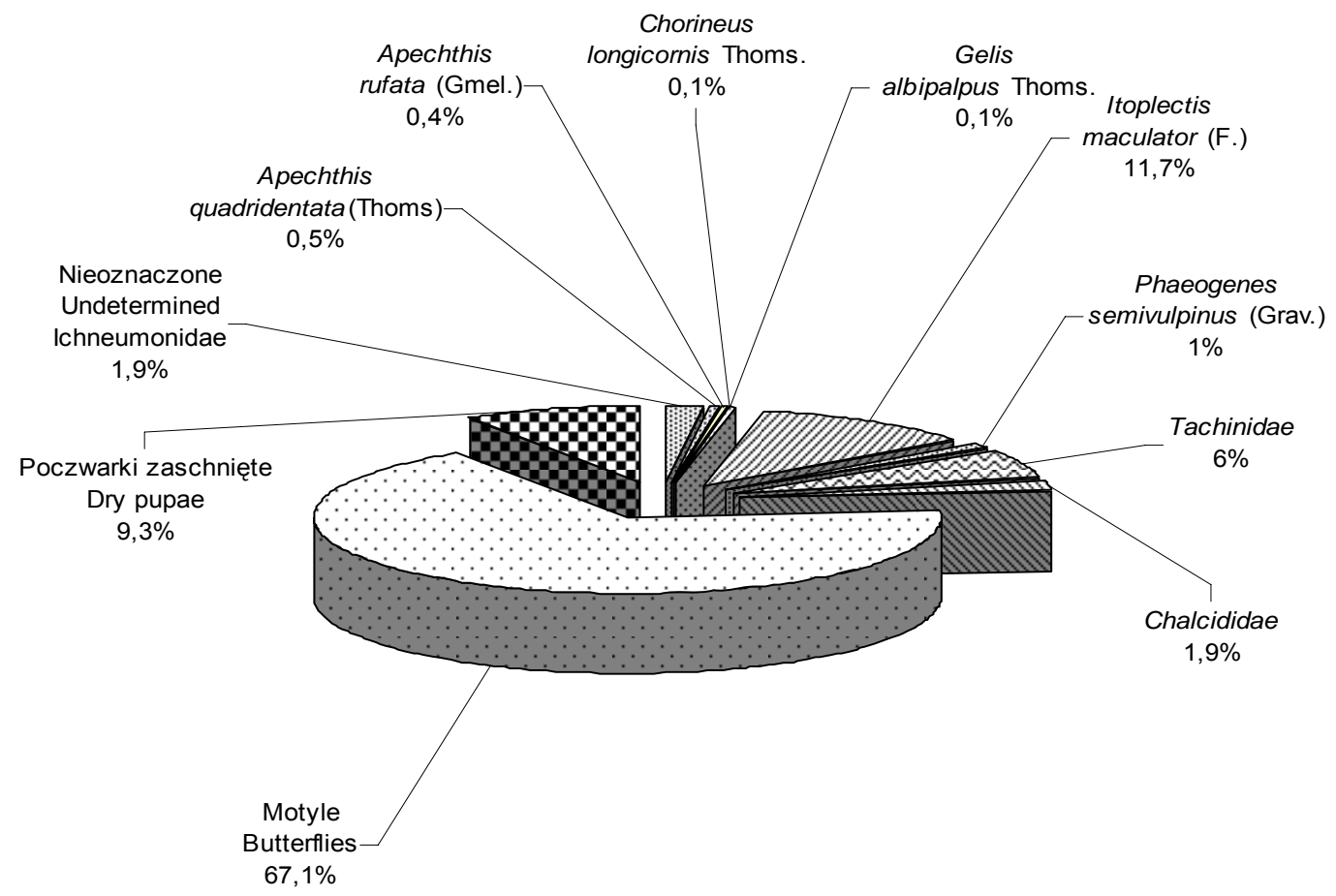

Rys. 2. Udział rodzin i gatunków Ichneumonidae w spasożytowaniu poczwarek A. rosana w 2010 roku

Fig. 2. The share families and Ichneumonidae species in parasitizing of A. rosana pupae in 2010

Obecne badania ustaliły wysoką skuteczność gatunku I. maculator w obniżaniu liczebności zwójki, ponieważ ten parazytoid spasożytował ją w najwyższym stopniu, bo w 4\% przy ogólnym spasożytowaniu wynoszącym 4,7\% oraz odpowiednio $11,7 \%$ przy spasożytowaniu $23,6 \%$. I. maculator jest gatunkiem bardzo stabilnym w środowisku sadowniczym i na tyle licznym, że należy do głównych entomofagów tej zwójki. Wcześniejsze badania
Piekarskiej-Bonieckiej (2004) oraz Piekarskiej-Bonieckiej i wsp. (2006, 2008) wykazały dominację tego gatunku w pasożytowaniu zwójki w sadach jabłoniowych na terenie Wielkopolski. Bardzo wysoki udział tego gatunku w kompleksie parazytoidów zwójek „liściowych” stwierdzili również Miczulski i Koślińska (1976) prowadząc badania w sadach jabłoniowych, w południowej Polsce. Z kolei Kot (2007) wykazała ten gatunek jako dominujący wśród 
entomofagów A. rosana w sadach, w południowej Polsce. Również Płuciennik i Olszak (2010) badając spasożytowanie zwójek ,liściowych" z dominującą wśród nich A. rosana w sadach jabłoniowych, w centralnej Polsce, stwierdzili zdecydowana dominację I. maculator. Aydoğdu i wsp. (2011) wykazali ten gatunek jako najliczniejszy wśród parazytoidów zwójki, żerującej w sadach czereśniowych, a Polat i Tozlu (2010) na drzewach i krzewach ozdobnych na terenie Turcji.

\section{Wnioski / Conclusions}

1. Wykazano odpowiednie warunki dla występowania entomofagów zwójki różóweczki [A. rosana (L.)] w sadach jabłoniowych, w których prowadzona jest integrowana ochrona roślin.

2. Stwierdzono wyraźne zróżnicowanie stopnia spasożytowania poczwarek zwójki różóweczki w sadach jabłoniowych.

3. Wykazano wysoką efektywność parazytoidów z rodziny Ichneumonidae (Hymenoptera, Apocrita) w regulacji liczebności zwójki różóweczki w porównaniu z pozostałymi rodzinami parazytoidów (Tachinidae, Chalcididae).

4. Stwierdzono wysoką skuteczność I. maculator (Ichneumonidae, Pimplinae) w obniżeniu liczebności zwójki w odniesieniu do pozostałych gatunków Ichneumonidae.

\section{Literatura / References}

Aydoğdu M., Beyarslan A., Yilmaz T. 2011. Organik kiraz bahçelerinde Archips rosana (Linnaeus, 1758) (Lepidoptera: Tortricidae) üzerinde gelişen parazitik arilar. Türkiye IV. Bitki Korusa Kongresi Bildirileri, 28-30 Haziran 2011, Kahramanmaraş, 452 ss.

Janiuk M., Gantner M., Kot I. 2011. Zwójki (Lepidoptera, Tortricidae) żerujące na krzewach borówki wysokiej (Vaccinium corymbosum L.) na plantacjach w okolicach Lublina. Prog. Plant Prot./Post. Ochr. Roślin 51 (3): 114-118.

Kot I. 2007. Parasitic entomofauna of leaf tortricids (Lepidoptera: Torticidae) occurring in apple orchards. EJPAU 10, 1,12 pp. http:/ejpau.media.pl/volume10/issnel/ary-27.htlm

Miczulski B., Koślińska M. 1976. Pasożytnicza entomofauna motyli zwójkowatych (Tortricidae) występujących w sadach jabłoniowych w niektórych rejonach Polski. Pol. Pismo Entomol. 46: 165-178.

Płuciennik Z., Olszak R.W. 2010. The role of parasitoids in limiting the harmfulness of leafrollers in apple orchards. J. Plant Prot. Res. 50 (1): $1-8$

Piekarska-Boniecka H. 2004. Natural control of rose tortrix moth Archips rosanus (L.) occurring in an apple orchard in Rosnowo. Rocz. AR Poznań 360, Ogrodn. 38: 119- 122.

Piekarska-Boniecka H., Wilkaniec B., Trzciński P., Borowiak-Sobkowiak B. 2006. Naturalna regulacja liczebności zwójki różóweczki [Archips rosana (L.)] występującej w sadzie jabłoniowym w Tarkowie w okolic Inowrocławia. Prog. Plant Prot./Post. Ochr. Roślin 46 (2): 495-497.

Piekarska-Boniecka H., Wilkaniec B., Dolańska-Niedbała E. 2008. Parazytoidy z rodziny Ichneumonidae (Hymenoptera, Apocrita) ograniczające liczebność zwójki różóweczki [Archips rosana (L.)] w wybranych sadach Wielkopolski. Prog. Plant Prot./Post. Ochr. Roślin 48 (4): 1319-1322.

Polat A., Tozlu G. 2010. Erzurum'da Archips rosana (Linnaeus, 1758) (Lepidoptera: Tortricidae)' nin kisa biyolojsi, konukçulari ve parazitoitleri üzerinde araştirmalar. Türk. Entomol. Derg. 4: 529-542. 